\title{
A Study Related to Effects of the Brucellosis on Osteoporosis
}

\author{
Hakan Sezgin Sayiner ${ }^{1}$, Sadık Akgün², Yunus Küçükkaya², Murat Alper \\ Başaran $^{3}$, *Hüseyin Vural ${ }^{4}$
}

${ }^{1}$ Department of Clinical Infectious Diseases, Faculty of Medicine, Adıyaman University, Adıyaman, Turkey. ${ }^{2}$ Department of Medical Microbiology, Faculty of Medicine, Adıyaman University, Adıyaman, Turkey. ${ }^{3}$ Department of Management Engineering, Faculty of Engineering, Alanya Alaaddin Keykubat University, Antalya,

Turkey. ${ }^{4}$ Department of Computer Technologies, Kahta Vocational School, Adıyaman University, Adıyaman, Turkey.

*Email: huseyinvural02@gmail.com

DOI: 10.31964/mltj.v1i1.269

\begin{abstract}
Brucellosis is one of the infectious diseases that may increase osteoporosis risk. Bone formation and destruction markers were analyzed in the examination of osteoporosis risk. There have been many studies on the effect of a variety of diseases on the bone, but no studies have conducted for brucellosis. This study is one of the rare studies showing the effect of brucellosis on a bone. The purpose of this study is that whether age, agglutination level, having brucellosis at the time or before, and gender knowledge of patients have effects on osteoporosis by using bone formation and destruction markers. Between 01/04/2015 and $31 / 12 / 2017$, blood samples were taken from 40 patients with brucellosis and seven patients whose treatment completed at least six months before. Then biochemical markers were studied on these blood samples. ELISA washer and reader (Biotek, Novatek, Istanbul, Turkey) was used to obtain the values of bone formation and destruction markers. There was a significant difference, according to $\mathrm{H}$. Osteocalcin (Human Osteocalcin/Bone Gla Protein), in terms of bone formation markers and was higher in women. Having brucellosis at the time was significant according to Human deoxypyridinoline (DPD) and Human C-telopeptide of type I collagen (CTX-I) in terms of bone destruction markers and was higher in brucellosis. The bone formation and destruction markers strongly correlated with each other in the same direction. It is thought that brucellosis can increase bone destruction markers, especially DPD (Human deoxypyridinoline) and CTX-I; therefore, osteoporosis risk in brucella patients can reduce by implementing a treatment plan that closely monitors bone destruction markers.
\end{abstract}

Keywords: Brucellosis; osteoporosis; bone formation; bone destruction.

\section{INTRODUCTION}

The bone is in the cycle of formation and destruction throughout the lifetime. The level of bone formation and destruction in normal conditions balances each other tightly (Markus, 2005). According to literature, an imbalance between bone formation and destruction can lead to bone diseases, including osteoporosis (Rinaldo et al., 2015). Osteoporosis is a systemic skeletal disease characterized by a decrease in bone mass and microstructural degradation, which may increase bone fragility and fracture danger and consequently cause serious complications (Van Den Bergh, Van Geel \& Geusens, 2012). The risk of osteoporosis increases due to age 
or some diseases or drug usage (Office of the Surgeon General, 2004). Brucellosis is an infectious disease (Alizadeh et al., 2018) and seen in our region, namely in the Mediterranean region (Bilgehan, 2000; Gotuzzo \& Cellillo, 1992). It mostly affects the musculoskeletal system. As far as we know, a few studies have done about the relationship between Brucella and osteoporosis. In one study, it was reported that Brucella could sometimes cause destructive septic arthritis in the joint, and osteoporotic appearance can be seen in the radiological image of this destructive arthritis in the advanced period (Günal et al., 2011). To estimate the relative risks of hip fracture in postmenopausal women, CTX-I has used, and it shows promise in predicting like these problems of osteoporosis (Swaminathan, 2001). DPD is particular for bone, in that it is found in relatively significant amounts only in bone and has been shown to correlate well with bone turnover (Robins, 1995). Col-I is the main constituent of the bone matrix. It is a significant marker of bone destruction (Eriksen et al., 1993).

We evaluated that brucellosis may affect the bone formation or bone resorption due to its relationship with the musculoskeletal system, so we analyzed whether brucellosis is risky in terms of osteoporosis. To evaluate the risk, we measured the effects of brucellosis on bone formation and destruction markers through our patients.

\section{MATERIALS AND METHODS}

Patients in this study were examined in the infection clinic with the suspicion of brucellosis between 01/04/2015 and 31/12/2017. The ethics committee report of this study approved by the presidency of Biomedical Research Ethics Committee, Medical Faculty, Adıyaman University, with approval code 2015/02-1 on 25/03/2015. Patients with clinical symptoms and with brucella coombs agglutination and wright agglutination test $1 / 160$ and above, diagnosed with Brucella, were included in the study. The number of these patients was 40 . The other seven patients included in the study came to the clinic for checking. They had completed the Brucella treatment at least six months ago and had no clinical findings since then. The effects of gender, agglutination level, and age knowledge of 47 patients in terms of bone formation markers, destruction markers, and bone formation/bone destruction values to measure the risk of osteoporosis. Biochemical markers were studied in these 47 blood samples taken from patients during diagnosis or follow-up.

Those biochemically used from these tests are $\mathrm{H}$. Osteocalcin (Human Osteocalcin/Bone Gla Protein), Human Procollagen I N-terminal peptide (PINP), Human bone alkaline phosphate (BALP), Human C-telopeptide of type I collagen (CTX-I), Human deoxypyridinoline (DPD) and Human collagen type I (Col-I). The first three markers are about the bone formation, and the last three markers are about bone destruction. Biochemical markers were obtained by the following methods.

\section{Patient Serums}

Twenty-one males and Twenty-six females, with a total of Forty-seven patients, were included in this study. Blood from these patients centrifuged for 10 minutes at 5000 rotations per minute (rpm), and the separated serums stored at $20^{\circ} \mathrm{C}$. Patient serums were warmed at room temperature before the study and were centrifuged again at 2000-3000 rpm for 10 to 20 minutes. The centrifugation repeated when sediments were formed during storage after the supernatants were carefully collected. Samples were stored at $-80^{\circ} \mathrm{C}$ for approximately three months to prevent biological activity and contamination loss. Hemolytic samples not included in 
the study since hemolysis in the samples would affect the test result. Samples brought to room temperature before testing.

Kits

The kits used in this study were $\mathrm{H}$. Osteocalcin, PINP, CTX-I, DPD, BALP, and Col-I (ELISA Kit, Shanghai YL Biotech Co, Ltd. YL biont, Jiading District, Shanghai). Each kit contained similar materials as content (Coated ELISA plate, Standard dilution, Chromogen solution A, and B and Streptavidin-HRP). TMB Substrate Wash Buffer and Stop Solution were stored at $4^{\circ} \mathrm{C}$ and others at $-20^{\circ} \mathrm{C}$ before opening. Kits were brought to room temperature and started to use. Some necessary materials prepared for the use of kits: Incubator that can provide stable incubation conditions up to $37^{\circ} \mathrm{C} \pm 0.5^{\circ} \mathrm{C}$, microplate reader with $450 \pm 10 \mathrm{~nm}$ filter, precision pipettes and disposable pipette tips, distilled water, absorbent paper, and gloves. Dilution of the standard solutions was started by adding $120 \mu \mathrm{l}$ of standard diluent to the original standard of $120 \mu \mathrm{l}$ in dilution ratio of $1280 \mathrm{nmol} / \mathrm{L}$ and by obtaining standard 5. Then, for serial dilutions; Standard 4 (320nmol / L) obtained by adding $120 \mu \mathrm{l}$ standard diluent to $120 \mu \mathrm{l}$ Standard 5, Standard 3 (160 $\mathrm{nmol} / \mathrm{L}$ ) obtained by adding $120 \mu \mathrm{l}$ standard diluent to $120 \mu \mathrm{l}$ Standard 4, Standard $2(80 \mathrm{nmol} /$ L) obtained by adding $120 \mu \mathrm{l}$ standard diluent to $120 \mu \mathrm{l}$ Standard 3, and Standard 1 (40nmol / L) was obtained by adding $120 \mu$ l standard diluent to $120 \mu$ l Standard 2. Quantitative measurement of in vitro $\mathrm{H}$. Osteocalcin, PINP, Col-I, CTX-I, DPD, BALP, and Col-I levels in serum, plasma, homogenized tissue, or other body fluids provided by sandwich enzyme immunoassay method.

Working Principles

The number of samples determined the number of strips needed to tested according to the standards. Three or more wells arranged, each containing a standard solution, empty well, and patient serum to tested. According to this, Chromogen solutions $A$ and $B$ and stop solution added to the empty well. $50 \mu l$ standard and streptavidin-HRP $50 \mu \mathrm{l}$ added to standard solution well. In the patient sample, well to be tested, $40 \mu \mathrm{l}$ of patient serum, and then $10 \mu \mathrm{l}$ of antibodies in the corresponding kit and $50 \mu \mathrm{l}$ of streptavidin-HRP were added. Then closed with plate membrane. The plates were then incubated at $37^{\circ} \mathrm{C}$ for 60 minutes with gentle shaking.

\section{ELISA Washer and Reader}

After incubation, washing concentration (30X) diluted with distilled water for later use. Carefully remove the plate membrane, empty the liquid, and rinse the remaining liquid. Each well filled with a washing solution. After waiting 30 seconds, the liquid was drained and then repeated five times by using an ELISA plate washer (Biotek, Novatek, İstanbul, Turkey). Then $50 \mu \mathrm{l}$ of chromogen A and $50 \mu \mathrm{l}$ of chromogen B solution were added to each well and shaken gently. Incubated for 10 minutes at $37^{\circ} \mathrm{C}$, away from light for color development. After that, a $50 \mu \mathrm{l}$ stop solution placed in all wells, and ELISA plate reader (Biotek, Novatek, İstanbul, Turkey) used for measuring at $450 \mathrm{~nm}$ wavelength within 10 minutes. Then, the wells drained entirely, and the absorbance (OD) of each well that had to perform within 10 minutes after the stop solution added measured under a wavelength of $450 \mathrm{~nm}$. 


\section{Computation of Results}

The concentration of the patient sample corresponding to the OD values calculated after calculating the linear regression equation of the standard curve according to the concentrations of the standards and the respective OD values.

\section{Statistical Analysis}

All data evaluated by Independent Sample t-Test and correlation analysis. The alpha value lower than $<0.05$ was considered significant for Independent Sample t-Test, and this shows that it is in the 95 percent confidence interval. In addition to available variables related to bone formation and destruction markers, we defined new variables using the idea of bone formation/bone destruction, which is by dividing two bone formation markers into three bone destruction markers. By doing so, we obtained ( $\mathrm{H}$. Osteocalcin)/(DPD), $(\mathrm{H}$. Osteocalcin $) /(\mathrm{CTX}-\mathrm{I}), \quad(\mathrm{H}$. Osteocalcin)/(Col-I), (BALP)/(DPD), (BALP)/(CTX-I) and (BALP)/(Col-I) values.

\section{RESULTS AND DISCUSSION \\ Gender}

The proportion of genders in this study is quite close to each other. An independent sample t-test was applied to denote, in which bone markers differ concerning gender attributes and the results shown in Table 1. According to results, $\mathrm{H}$. Osteocalcin differed between males and females at the level of significance $(0.034<0.05)$ and was higher in women. On the other hand, there could be another bone marker candidate called BALP if the sample size could increase since its significance value $(0.076)$ is very close to 0.05 .

Table 1. The Results of Gender in Terms of Bone Formation Markers.

\begin{tabular}{|c|c|c|c|c|c|c|}
\hline \multicolumn{7}{|c|}{ Levene's Test for Equality of Variances } \\
\hline & & F & Sig & $\mathrm{t}$ & df & $\begin{array}{l}\text { Sig. }(2 \\
\text { tailed) }\end{array}$ \\
\hline Human & $\begin{array}{l}\text { Equal variances } \\
\text { assumed }\end{array}$ & ,397 & $\begin{array}{c}, 53 \\
2\end{array}$ & ,727 & 45 & ,471 \\
\hline $\begin{array}{l}\text { Procollagen I N- } \\
\text { terminal peptide }\end{array}$ & $\begin{array}{l}\text { Equal variances } \\
\text { not assumed }\end{array}$ & & & ,727 & 42,975 & ,471 \\
\hline Human bone & $\begin{array}{l}\text { Equal variances } \\
\text { assumed }\end{array}$ & 1,064 & ,308 & 1,816 & 45 & 076 \\
\hline $\begin{array}{l}\text { alkaline } \\
\text { phosphate }\end{array}$ & $\begin{array}{l}\text { Equal variances } \\
\text { not assumed }\end{array}$ & & & 1,851 & 44,925 & ,071 \\
\hline $\mathrm{H}$. & $\begin{array}{l}\text { Equal variances } \\
\text { assumed }\end{array}$ & 7,878 & 007 & 2,095 & 45 & ,042 \\
\hline Osteocalcin & $\begin{array}{l}\text { Equal variances } \\
\text { not assumed }\end{array}$ & & & 2,195 & 42,777 & ,034 \\
\hline
\end{tabular}

An independent sample t-test also performed to denote which bone destruction markers differ concerning gender and the results shown in Table 2. According to the results, none of the bone destruction markers is statistically significant concerning gender attributes. On the other hand, if the sample size increased, there would be a potential candidate, which is CTX-I, since its significance value $(0.073)$ is very close to 0.05 . Besides, there was no statistical significance between bone formation/bone destruction values and gender. 
Table 2. The Results of Gender in Terms of Bone Destruction Markers.

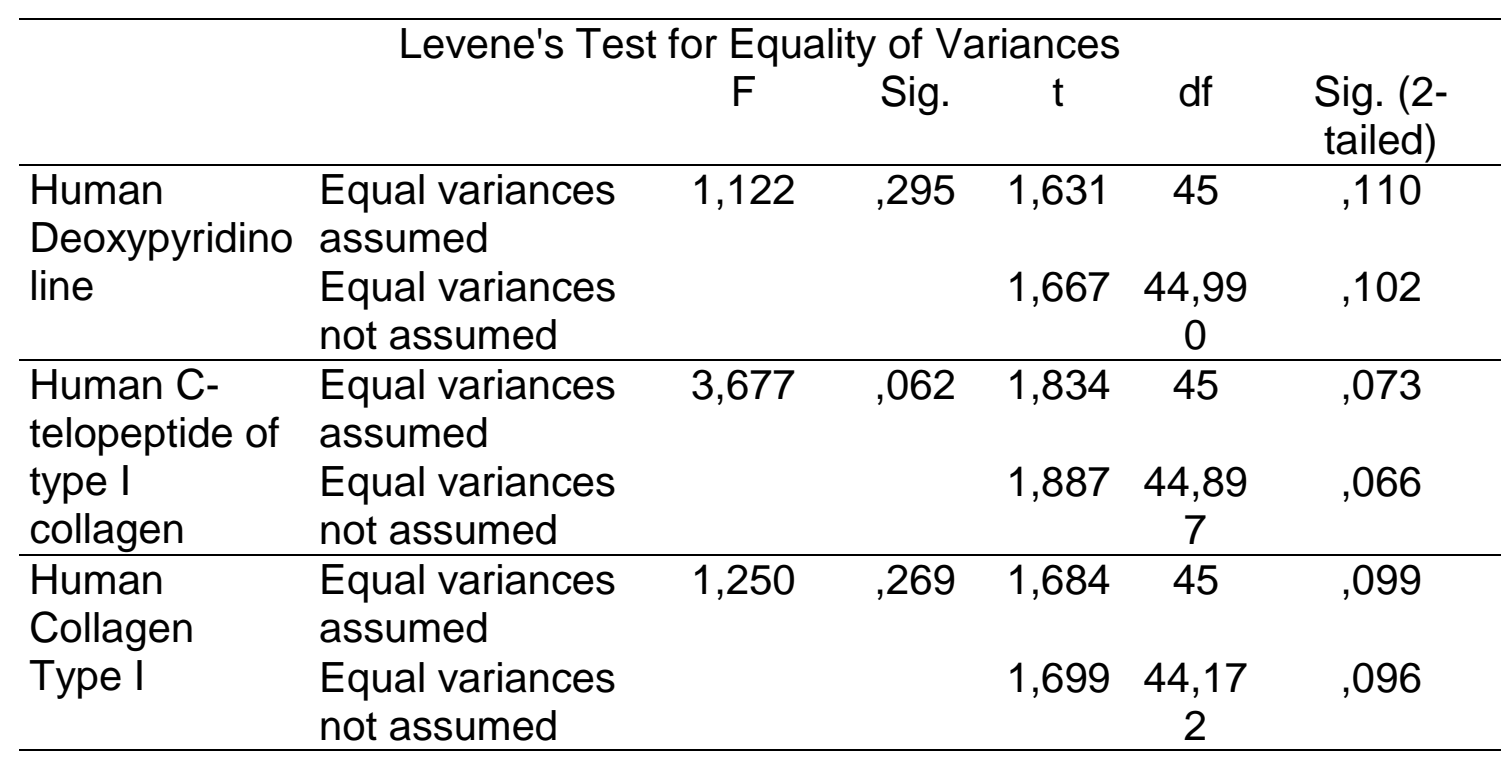

\section{Having Brucellosis at the Time or Before}

The number of patients we evaluated in this study was 47 . At the time of the study, the number of patients with brucellosis was 40 , while the number of patients who had brucellosis before was 7 . An independent two-sample t-test performed to denote which bone markers differ when patients are at a stage of having brucellosis or having it before; the obtained results shown in Table 3.

Table 3. The Results of Having Acute Brucellosis at The Time or Before in Terms of Bone Formation Markers.

\begin{tabular}{|c|c|c|c|c|c|c|}
\hline \multicolumn{7}{|c|}{ Levene's Test for Equality of Variances } \\
\hline & & & Sig. & $\mathrm{t}$ & df & Sig (2-tailed) \\
\hline $\begin{array}{l}\text { Human } \\
\text { Procollagen I }\end{array}$ & $\begin{array}{l}\text { Equal variances } \\
\text { assumed }\end{array}$ & 2,033 & ,161 & $-1,249$ & 45 & ,218 \\
\hline $\begin{array}{l}\text { N-terminal } \\
\text { peptide }\end{array}$ & $\begin{array}{l}\text { Equal variances } \\
\text { not assumed }\end{array}$ & & & $-1,668$ & 11,530 & 122 \\
\hline $\begin{array}{l}\text { Human bone } \\
\text { alkaline }\end{array}$ & $\begin{array}{l}\text { Equal variances } \\
\text { assumed }\end{array}$ & 1,867 & 179 & - & 45 & ,420 \\
\hline phosphate & $\begin{array}{l}\text { Equal variances } \\
\text { not assumed }\end{array}$ & & & $-1,201$ & 13,837 & 250 \\
\hline $\mathrm{H}$. & $\begin{array}{l}\text { Equal variances } \\
\text { assumed }\end{array}$ & 4,855 & ,033 & $-1,137$ & 45 & , 262 \\
\hline Osteocalcin & $\begin{array}{l}\text { Equal variances } \\
\text { not assumed }\end{array}$ & & & $-2,030$ & 23,064 & ,054 \\
\hline
\end{tabular}

Even though none of them is statistically significant, one of them, $\mathrm{H}$. Osteocalcin, with 0.054 significance level, would be potentially found significant if the sample size increased.

Table 4 denotes which bone destruction markers differ when patients are at a stage of having brucellosis or having it before. We here run an independent twosample t-test. Two of them, DPD and CTX-I, are found statistically significant since 
their significance levels are $(0.024<0.05)$ and $(0.106<0.05)$, respectively. If the sample size increased, then the third one, Col-I, would also be found statistically significant since its significance level $(0.054)$ is very close to 0.05 .

Table 4. The Results of Having Acute Brucellosis at The Time or Before in Terms of Bone Destruction Markers.

\begin{tabular}{lllllll}
\hline & Levene's Test for Equality of Variances & & \\
& & F & Sig. & T & df & Sig. (2- \\
& & & & & & tailed) \\
\hline \multirow{2}{*}{$\begin{array}{l}\text { Human } \\
\text { deoxypyridinoline }\end{array}$} & $\begin{array}{l}\text { Equal variances } \\
\text { assumed }\end{array}$ & 3,824 &, 057 & $-1,394$ & 45 &, 170 \\
& $\begin{array}{l}\text { Equal variances } \\
\text { not assumed }\end{array}$ & & & $-2,434$ & 21,471 &, 024 \\
\hline $\begin{array}{l}\text { Human C- } \\
\text { telopeptide of } \\
\text { type I collagen }\end{array}$ & $\begin{array}{l}\text { Equal variances } \\
\text { assumed }\end{array}$ & 5,137 &, 028 & $-1,797$ & 45 &, 079 \\
\hline $\begin{array}{l}\text { Equal variances } \\
\text { not assumed }\end{array}$ & & & $-2,711$ & 14,521 &, 016 \\
\hline $\begin{array}{l}\text { Human Collagen } \\
\text { Type I }\end{array}$ & $\begin{array}{l}\text { Equal variances } \\
\text { assumed } \\
\text { Equal variances } \\
\text { not assumed }\end{array}$ & 1,876 &, 178 & $-1,674$ & 45 &, 101 \\
\hline
\end{tabular}

We examined the results between having brucellosis at the time or before with bone formation/bone destruction values. There was no statistical significance between having brucellosis at the time or having it before concerning the bone formation/bone destruction values.

\section{Age and Agglutination Level}

Table 5 shows the correlation between the attributes (bone markers). The first one is PINP and BALP with 0.86, which means that there is a strong linear relationship between those. The second one is PINP and $\mathrm{H}$. Osteocalcin with 0.81 , which means that there is a strong linear relation between them. The third one is BALP and $\mathrm{H}$. Osteocalcin, with 0.88 , which means that there is a strong linear relation between them. We here run correlation analysis among the attributes presented in Table 5. Also, Age is not a statistically significant variable with bone markers. The same is true for the Agglutination level.

Table 6 shows the correlation among the attributes (bone destruction markers). The first one is DPD and CTX-I with 0.939, which means that there is a solid linear relation between those. The second one is DPD and Col-I with 0.922, which means that there is a solid linear relation between them. The third one is CTXI and Col-I with 0.904, which means that there is a solid linear relation between them. We here run correlation analysis among the attributes presented in Table 6. Also, Age is not a statistically significant variable with bone destruction markers. The same is true for the Agglutination level.

The correlations among bone formation/bone destruction markers with age and agglutination were analyzed. Age and agglutination levels are not found statistically significant with them. However, there exist both high and low correlations among them. Here we sample the highest and the lowest significant correlations. While the highest correlation between (BALD)/(DPD) and (H. Osteocalcin)/(DPD) is 0.99 , the lowest correlation between $(\mathrm{H}$. Osteocalcin $) /(\mathrm{CTX}-\mathrm{I})$ and $(\mathrm{BALP}) /(\mathrm{COL}-\mathrm{I})$ is 0.36 . 
According to results, the cycle of bone formation and bone destruction continue as routine in brucellosis patients. DPD and CTX-I levels are found significant in brucellosis patients.

Table 5. The Results of Correlation Analysis of Age, Agglutination Level Concerning Bone Formation Markers.

\begin{tabular}{|c|c|c|c|c|c|c|}
\hline & & & Jorrelations & & & \\
\hline & & Age & $\begin{array}{l}\text { Agglutina } \\
\text { tion Level }\end{array}$ & $\begin{array}{l}\text { Human } \\
\text { Procolla } \\
\text { gen I N- } \\
\text { terminal } \\
\text { peptide }\end{array}$ & $\begin{array}{l}\text { Human } \\
\text { bone } \\
\text { alkaline } \\
\text { phosph } \\
\text { ate }\end{array}$ & $\begin{array}{c}\mathrm{H} . \\
\text { Osteoca } \\
\text { Icin }\end{array}$ \\
\hline & $\begin{array}{l}\text { Pearson } \\
\text { Correlation }\end{array}$ & 1 &,- 028 & ,240 & ,223 & ,284 \\
\hline Age & Sig. (2-tailed) & & ,850 & , 104 & , 131 & ,053 \\
\hline & $\mathrm{N}$ & 47 & 47 & 47 & 47 & 47 \\
\hline Agglutinati & $\begin{array}{l}\text { Pearson } \\
\text { Correlation }\end{array}$ &,- 028 & 1 &,- 012 & ,090 & , 137 \\
\hline & Sig. (2-tailed) & ,850 & & ,939 & ,549 & ,360 \\
\hline Level & $\mathrm{N}$ & 47 & 47 & 47 & 47 & 47 \\
\hline $\begin{array}{l}\text { Human } \\
\text { Procolla- }\end{array}$ & $\begin{array}{l}\text { Pearson } \\
\text { Correlation }\end{array}$ & ,240 &,- 012 & 1 &, $861^{* *}$ &, $810^{* *}$ \\
\hline gen I N- & Sig. (2-tailed) & ,104 & ,939 & & ,000 & ,000 \\
\hline $\begin{array}{l}\text { terminal } \\
\text { peptide }\end{array}$ & $\mathrm{N}$ & 47 & 47 & 47 & 47 & 47 \\
\hline $\begin{array}{l}\text { Human } \\
\text { bone }\end{array}$ & $\begin{array}{l}\text { Pearson } \\
\text { Correlation }\end{array}$ & ,223 & ,090 & $861^{* *}$ & 1 &, $882^{* *}$ \\
\hline alkaline & Sig. (2-tailed) & , 131 &, 549 &, 000 & & ,000 \\
\hline phosphate & $\mathrm{N}$ & 47 & 47 & 47 & 47 & 47 \\
\hline $\mathrm{H}$. & $\begin{array}{l}\text { Pearson } \\
\text { Correlation }\end{array}$ & ,284 & ,137 &, $810^{* *}$ &, $882^{\text {x* }}$ & 1 \\
\hline Osteocalc & Sig. (2-tailed) & ,053 & ,360 & ,000 & ,000 & \\
\hline in & $\mathrm{N}$ & 47 & 47 & 47 & 47 & 47 \\
\hline
\end{tabular}

Bone formation and destruction are like a cycle; it continues throughout life. When the accumulative influence of bone destruction and deterioration of bone structure happen, then osteoporosis can be developed (Rinaldo et al., 2015). Osteoporosis can cause fractures, so people who have osteoporosis are at high risk. Primary osteoporosis is known as the most common form of osteoporosis, and primary osteoporosis is seen in the old ages because they suffer from excessive bone destruction. The reason why excessive bone destruction frequently happens is the disruption of the cycle of bone formation and destruction (4). Brucellosis is also an infectious disease, and in this study, we aimed to evaluate the relationship between brucellosis and risk of osteoporosis through the bone markers. It is seen that bone formation and destruction markers were correlated. Previous studies have been conducted to analyze the relationship between osteoporosis and different diseases through bone markers: In a study, Biochemical markers linked with bone 
remodeling, including $\mathrm{N}$-serum terminal propeptide of type 1 procollagen (sPINP) and serum Cross-linked C telopeptides of type I collagen (sCTX1) are significantly associated with the risk of future osteoporotic vertebral fractures. It was found that the combined use of bone markers and a history of previous fractures determined osteoporotic fracture risk in postmenopausal women (Ivaska et al., 2010).

Table 6. The Results of Correlation Analysis of Age, Agglutination Level Concerning Bone Destruction Markers.

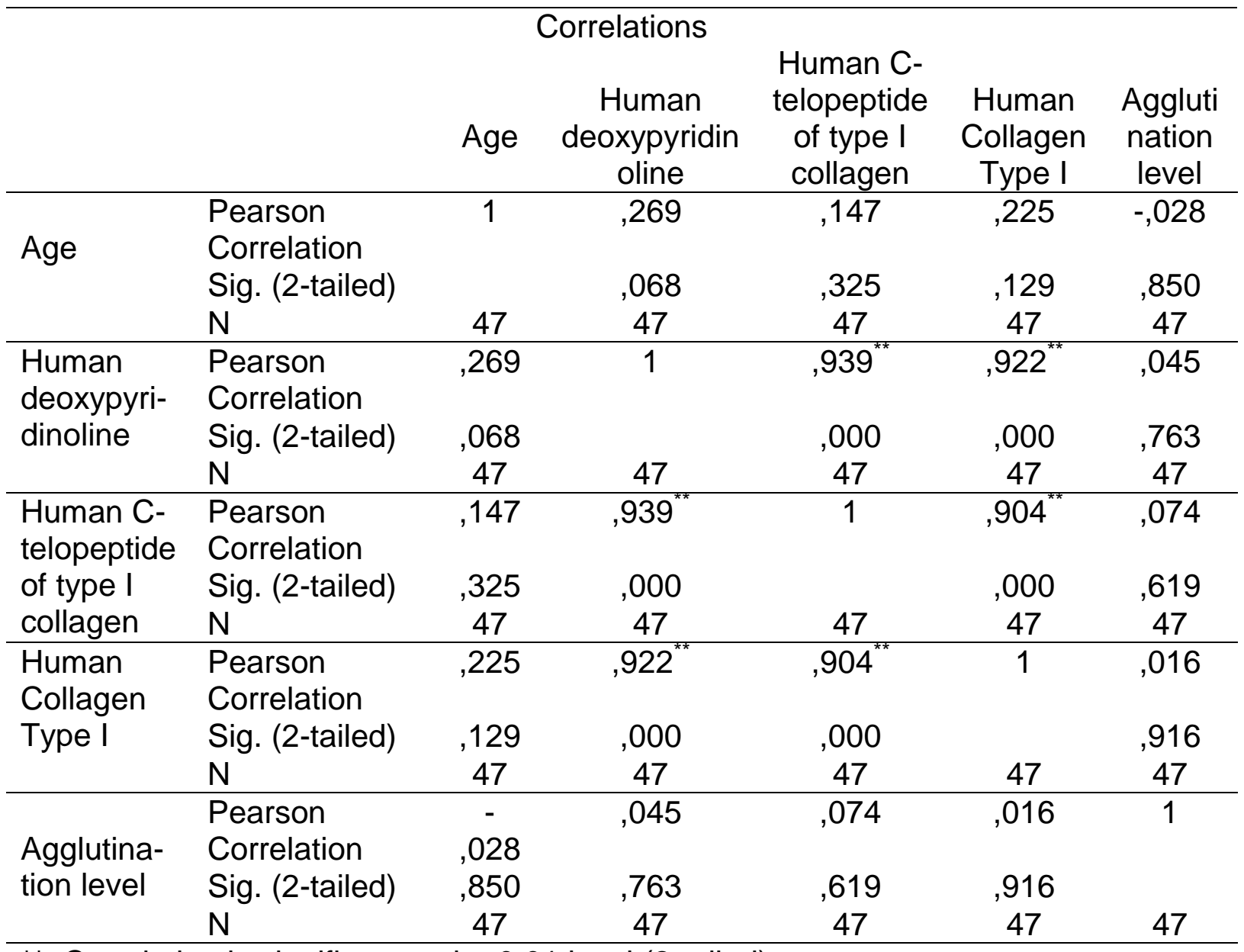

**. Correlation is significant at the 0.01 level (2-tailed).

In another study, the association between osteoporosis, obesity, and type 2 diabetes measured by researchers. Lower fasting bone turnover markers, Osteocalcin, and collagen type 1 cross-linked C-terminal telopeptide found to suppressed in insulin resistance independent of adiposity (Tonks et al., 2017). In this study, we found that gender was of significance in terms of $\mathrm{H}$. Osteocalcin, and this significance was higher in women. Besides, if the number of data increased, then there may be a high chance that having brucellosis at the time or before might be significant in terms of $\mathrm{H}$. Osteocalcin. When we analyzed having brucellosis at the time or before in terms of bone destruction markers, it was found that CTX-I is statistically significant. In this study, we have evaluated that if the data set increased, gender has the potential to be significant in terms of BALP, and also, there is no significance for gender in terms of bone destruction markers. When we analyzed having brucellosis at the time or before in terms of bone formation and 
bone destruction markers, we found that statistically having brucellosis at the time or before had no significance in the case of bone formation markers. In another study, while those who have diabetes had lower C-terminal of type 1 collagen (CTx) levels than those who did not overall, those with diabetes and high CTx levels had a 3.5fold increase in total fracture rates. Nevertheless, the rise in vertebral fracture did not reach statistical significance compared to nondiabetic individuals with high CTx (Alexander et al., 2018). In another study, by dividing different values of PINP to different values of beta C-terminal cross-linked telopeptide of type I collagen (bCTX), a classification model for bone turnover status as six subtypes were recommended by researchers. Afterward, in orthogeriatric patients, altered subtypes were shown to be closely related to the presence of nonvertebral fractures, comorbidities, and poorer in-hospital outcomes (Jiajue et al., 2014).

In this study, we evaluated gender, having brucellosis at the time or before, agglutination level, age in terms of the values that we obtained by dividing bone formation markers/bone destruction markers, and found that there was no significance. The weak point of this study was that bone densitometry could not be performed in patients, and radiological imaging methods could not be performed because of the absence of ileitis and spondylodiscitis findings, so skeletal involvement could not be evaluated in patients.

\section{CONCLUSION}

In conclusion, the bone formation and bone destruction cycle of brucellosis patients continue as a routine. In patients with brucellosis, DPD, and CTX-I, which are bone destruction markers, increased. It is thought that it may be a risk factor for osteoporosis in later stages. In these patients, treatment planning options may be given in order to prevent the development of osteoporosis in the early period by following the bone destruction markers, but more studies are needed.

\section{ACKNOWLEDGMENTS}

This study was conducted with the support of the Adiyaman University Tipfmap /2015-0001 Scientific Research Project. All authors who are Hakan Sezgin Sayiner, Sadık Akgün, Yunus Küçükkaya, Murat Alper Başaran, and Hüseyin Vural declare that they have no conflict of interest and do not have an interest-based relationship.

\section{CONFLICT OF INTEREST}

This study received approval from the presidency of Biomedical Research Ethics Committee, Medical Faculty, Adıyaman University, Adıyaman, Turkey, with approval code $2015 / 02-1$ on $25 / 03 / 2015$. The authors declare that there is no conflict of interest in this research.

\section{REFERENCES}

Alexander, F., Leon, F., Wichat, S., Paul, N.S., (2018). Bone Turnover Status: Classification Model and Clinical Implications. Int J Med Sci, 15(4), 323-338.

Alizadeh M., Safarzadeh A., Bahmani M., Beyranvand F., Mohammadi M., Azarbaijani K., Rafieian-Kopaei M., Abbaszadeh S. (2018). Brucellosis: Pathophysiology and new promising treatments with medicinal plants and natural antioxidants. Asian Pac J Trop Med, 11(11), 597-608.

Bilgehan, H. (2000). Klinik Mikrobiyoloji Ozel Bakteriyoloji ve Bakteri Enfeksiyonları. Izmir: Barıs Yayınları Fakulteler Kitabevi. 
Eriksen, E.F., Charles, P., Melsen, F., Mosekilde, L., Risteli, L. Risteli, J. (1993). Serum markers of type 1 collagen formation and degradation in metabolic bone disease: correlation with bone histomorphometry. J Bone Miner Res, 8(2), 12732.

Gotuzzo, E., Cellillo, C. (1992). Brucellosis. In: Gorbach SL, Bartlett JG, Blacklow $N R$ (eds). Infectious Diseases. (2nd ed.). W.B. Saunders Co. Philadelphia (pp. 1513-21).

Günal, Ö., Ülger, F., Barut, Ş., Ülger, A. (2011). Osteoartiküler Bruselloz. Klimik Dergisi, 24(2), 76-81.

Ivaska, K.K., Gerdhem, P., Väänänen, H.K., Akesson, K., Obrant, K.J. (2010). Bone turnover markers and prediction of fracture: a prospective follow-up study of 1,040 elderly women for a mean of 9 years. Journal of Bone and Mineral Research, 25(2), 393-403.

Jiajue, R., Jiang, Y., Wang, O., Li, M., Xing, X. et al., (2014). Suppressed bone turnover was associated with increased osteoporotic fracture risks in non-obese postmenopausal Chinese women with type 2 diabetes mellitus. Osteoporosis Int, 25(8), 1999-2005.

Markus, J.S. (2005). Biochemical Markers of Bone Turnover Part I: Biochemistry and Variability. Clin Biochem Rev, 26(4), 97-122.

Office of the Surgeon General (US) Bone health and osteoporosis: a report of the surgeon general. Office of the Surgeon General (US); Rockville: 2004.

Rinaldo, F.S., Gisela, S., Estela, S.C., Manuel, J.S., Paulo, S.C. (2015). Biology of Bone Tissue: Structure, Function, and Factors That Influence Bone Cells. Biomed Res Int, 2015: 421746.

Robins, S.P. (1995). Collagen crosslinks in metabolic bone disease. Acta Orthop Scand, 266, 171-5.

Swaminathan, R. (2001). Biochemical markers of bone turnover. Clin Chim Acta, 313(1-2), 95-105.

Tonks, K.T., White, C.P., Center, J.R., Samocha, B.D., Greenfield, J.R. (2017). Bone Turnover Is Suppressed in Insulin Resistance, Independent of Adiposity. J Clin Endocrinol Metab, 102(4), 1112-1121.

Van Den Bergh, J.P., Van Geel, T.A., Geusens, P.P. (2012). Osteoporosis, frailty, and fracture: implications for case finding and therapy. Nat Rev Rheumatol, $8(3), 163-72$. 